\title{
A Study on Lung Cancer in Jianghan Plain
}

\author{
Kun Zhang1 ${ }^{*}$, Man $\mathrm{Li}^{2}$, Yanhua Zhang ${ }^{3}$, Xiaochun Peng ${ }^{3 \#}$ \\ ${ }^{1}$ Department of Anesthesiology, Jingzhou Central Hospital, Affiliated to Medical School of Yangtze University, \\ Jingzhou, China \\ ${ }^{2}$ Department of Oncology, Jingzhou Central Hospital, Affiliated to Medical School of Yangtze University, \\ Jingzhou, China \\ ${ }^{3}$ Medical School of Yangtze University, Jingzhou, China \\ Email: "pxcwd789@sina.com
}

Received 20 April 2014; revised 24 May 2014; accepted 1 June 2014

Copyright (C) 2014 by authors and Scientific Research Publishing Inc.

This work is licensed under the Creative Commons Attribution International License (CC BY).

http://creativecommons.org/licenses/by/4.0/

(c) (i) Open Access

\section{Abstract}

This study was to investigate the epidemiology of lung cancer in Jianghan Plain, providing scientific basis for prevention and treatment of lung cancer. Pathology and clinical data of 1290 patients diagnosed lung cancer from the largest hospital in Jianghan Plain were collected and analyzed. Results found that the lung cancer incidence increased gradually from the age of 40 and at the peak during 61 to 70 years old; the male to female ratio was 2.45:1; Smoking patients were 841 cases, accounting for $65.2 \%$ of all cases. Smoke index $>400$ was 771 cases accounting for 91.7 percent of smokers and smoking index $<400$ was 70 cases accounting for $8.3 \%$ of smoking patients. $93.6 \%$ of the patients were to start smoking at a young age. The rate of patient pathological cytology diagnosed by fiberoptic bronchoscopy was $31.8 \%$, which showed that it was an important diagnostic method for lung cancer. The main reason for smoking is to break up the monotony and although many patients know nicotine, carbon monoxide is the main smoking harmful substances and smoking may cause lung cancer; not many people can take the initiative to quit smoking. It also showed that squamous cell carcinoma was the main type in smoking patients, while adenocarcinoma in non-smoking patients. The comprehensive epidemiological analysis suggested that smoking is an important factor in causing lung cancer, smoking cessation education and regular medical examinations to strengthen the prevention of lung cancer have a positive meaning to their family members.

\section{Keywords}

Lung Cancer, Smoking, Therapy

\footnotetext{
*These authors contributed equally to this work and should be considered co-first authors

\#Corresponding author.
} 


\section{Introduction}

Smoking is widespread in China [1]. China consumed more than 38\% of the world's cigarettes in 2009. More cigarettes were consumed in China than those in the other top four tobacco-consuming countries combined. In 2010, 41\% of the world's cigarettes were produced in China. Bernhard Schwartländer also noted that Chinese male smoking rate was $50.4 \%$, about 340 million people are at great risk of death due to tobacco use; $12 \%$ of male deaths attributed to tobacco use, and this figure may increased significantly. Tobacco use is a major risk factor for death from heart attacks and strokes [2]. Worldwide, smoking causes almost $80 \%$ of male and nearly $50 \%$ of female lung cancer deaths. Smoking increases the risk of tuberculosis (TB) infection, and 40 million smokers with TB are expected to die between 2010 and 2050. By the year 2030, 8 million people will die from tobacco use annually. In recent years, lung cancer incidence and mortality also increased significantly, having become China's largest cancer. In order to understand the situation of lung cancer in the Jianghan Plain, pathology and clinical data of 1290 patients diagnosed lung cancer from the largest hospital in Jianghan Plain were collected and analyzed as follows.

\section{Methods}

\subsection{Participants}

2013-2014 in Jingzhou Central Hospital for treatment of 1290 cases of lung cancer were diagnosed by pathological tissue cells.

\subsection{Trial Design}

Self-made questionnaire was used on the patient's general condition, life and behavior, smoking cognitive.

\section{Results}

Table 1 gives the age distribution of the patients. The group of 1290 cases of patients, male 916 cases, female 374 cases, and the ratio of male to female was 2.45:1; aged from 15 to 92 years old. Smoking patients were 841 cases, 758 cases male and 83 cases female, accounting for $65.2 \%$ of all cases. Smoke index $>400$ was 771 cases, accounting for $91.7 \%$ of patients with smoking; smoking index $<400$ was 70 cases, accounting for $8.3 \%$ of smoking patients. Only 65 cases started smoking over age 40, the rest were to start smoking at a young age accounted for $93.6 \%$ of the patients.

Table 2 gives the pathological tissue typing of the patients. It showed that squamous cell carcinoma was the main type in smoking patients, while adenocarcinoma in non-smoking patients.

Table 3 gives the Diagnostic tissue-derived methods.

Table 4 gives causes of smoking and cognitive about the danger. The main reason for 55.2\% of people is to break up the monotony, the rest is socializing, curiosity or fashion. About "Smoking is hazardous to health" point of view, $78.0 \%$ of people agreed and said it would cut less smoking; $98.5 \%$ of people know that smoking may cause lung cancer; $92.0 \%$ of people know nicotine, carbon monoxide is the main smoking harmful substances.

In the 1290 cases, there are many metastasis: 45 cases in supraclavicular lymph node metastasis, accounting for $3.5 \%$; 183 cases in lung door lymph node metastasis, accounting for $14.2 \%$; 151 cases in mediastinal lymph node metastasis, accounting for $11.7 \%$; 55 patients in bone metastases, accounting for $4.3 \%$; 47 cases in brain metastasis, accounting for $3.6 \%$; pericardial Transferred 15 cases, accounting for $1.2 \%$; 9 cases in liver metastases, accounting for $0.7 \%$.

Table 1. Age distribution of the patients.

\begin{tabular}{ccc}
\hline Age distribution & Cases & \% \\
\hline $15-40$ & 39 & 3.0 \\
$41-50$ & 181 & 14.0 \\
$51-60$ & 414 & 32.1 \\
$61-70$ & 450 & 34.9 \\
$>70$ & 206 & 16.0 \\
\hline
\end{tabular}


Table 2. Pathological tissue typing.

\begin{tabular}{ccccc}
\hline \multirow{2}{*}{ Pathological tissue typing } & \multicolumn{2}{c}{ Smoking } & \multicolumn{2}{c}{ No smoking } \\
\cline { 2 - 5 } & $\mathrm{n}$ & $\%$ & $\mathrm{n}$ & $\%$ \\
\hline Squamous cell carcinoma & 414 & 49.2 & 35 & 7.5 \\
Small cell carcinoma & 54 & 6.4 & 258 & 57.5 \\
Adenocarcinoma & 264 & 81.4 & - & 2.2 \\
Large cell carcinoma & 68 & 3.9 & 10 & \\
Adeno-squamous & 33 & 1.0 & - & \\
Carcinoid & 8 & & & \\
\hline
\end{tabular}

Table 3. Diagnostic tissue-derived methods.

\begin{tabular}{ccc}
\hline Methods & Cases & \% \\
\hline Bronchoscopy & 410 & 31.8 \\
Percutaneous lung biopsy & 82 & 6.4 \\
Pleural biopsy & 23 & 1.8 \\
Lymph node biopsy & 20 & 1.6 \\
Pleural effusion & 61 & 4.7 \\
Surgery & 694 & 53.8 \\
\hline
\end{tabular}

Table 4. Why smoking.

\begin{tabular}{cccc}
\hline Causes & Cases & \% \\
\hline Break up the monotony & 712 & 261 & 20.2 \\
Socializing & 136 & 10.5 \\
Curiosity & 181 & 14.1 \\
Fashion & 18 & \\
\hline
\end{tabular}

\section{Discussion}

Lung cancer is the high incidence and high mortality, relatively poor treatment of malignant tumors [3], the incidence of many factors. Domestic and international data indicated that the main risk of lung cancer risk factors is smoking; cigarette carcinogens can act directly on bronchial skin, induced mutations and the formation of lung cancer [4]-[6]. The patients accounted for $62.4 \%$ of smokers, tips closely related to lung cancer and smoking. And $91.3 \%$ of smokers smoking index was above 400 , and $93.6 \%$ patients were to start smoking at a young age. Therefore, actively promoting smoking cessation, especially from the start of its young people, is an important measure to prevent lung cancer, but most smokers still have no determination to know the dangers of smoking cessation. Therefore, the establishment of strengthening and improving the cessation door diagnosis, psychological, physiological and other multi-angle to help smokers quit is completed, thus improving quit smoke success rate. Studies have shown that quitting makes the risk of lung cancer with smoking cessation and decreased year extension, for 15 years before quitting and non-smokers are similar. Therefore, smokers in smoking cessation clinic still in a need to complete a long-term follow-up, can not be ignored. Even brief tobacco cessation interventions are effective [7]-[9].

This group of patients showed that the incidence of lung cancer increasing from the age of 40 gradually, as 40 to 50 years old accounted for $14 \%$; 51 to 60 years old accounted for $32.1 \%$; 61 to 70 years accounted for $34.9 \%$ to the peak; teenagers' prevalence was $3.0 \%$, should be vigilant. It was consisted with that reported [10].

Cough, hemoptysis, chest pain, shortness of breath, weight loss, fever are the main clinical manifestations of the disease now [11], about $54.5 \%, 24.8 \%, 23.6 \%, 2.9 \%, 10.6 \%, 6.7 \%$ respectively, extra-pulmonary manifestations of lung cancer symptoms can be a pioneer. This group of patients, the first bone metastasis disease cases accounted for $1.2 \%$. It is therefore recommended over age 40 , especially in the lungs of smokers above manifestations, especially in the presence of multiple symptoms together, to be highly vigilant lung cancer, as early further checks to confirm the diagnosis. 
The main reason for smoking is to break up the monotony; the rest is socializing, curiosity or fashion. Although many patients know nicotine, carbon monoxide is the main smoking harmful substances and smoking may cause lung cancer, not many people can take the initiative to quit smoking. So smoking cessation education and regular medical examinations to strengthen the prevention of lung cancer are necessary.

Currently, the pathological diagnosis of lung cancer is still the gold standard for diagnosis [12]. The rate of patient pathological cytology diagnosed by fiberoptic bronchoscopy was $31.8 \%$, which showed that it was an important diagnostic method for lung cancer, should create conditions to carry out the popularity, combined with pleural biopsy, lymph node biopsy, pleural effusion checks and other methods to improve the diagnosis of lung cancer level [13]. X-ray and CT examination are the most common cancer diagnostic imaging methods. The group of five cases misdiagnosed as tuberculosis, suggesting the presence of some of the lack of specific signs of lung cancer atypical imaging, imaging alone is difficult to confirm the diagnosis, therefore, and early surgery and surgical exploration for cell diagnostic pathology is particularly important.

Radical surgery is a recognized means of lung cancer. Who suffer from lung cancer after surgery is evident, especially long-term survival rate, the earlier the treatment, the long-term survival rate is higher. Most of the patients were transferred to have emerged, including hilar and mediastinal lymph nodes which were $14.2 \%, 11.7 \%$; supra-clavicular lymph node metastasis was 3.5\%, asymptomatic cancer accounted for by physical examination $9.3 \%$. At present, more than $80 \%$ of the patients to the hospital are already late, because this periodic medical examination of high-risk groups, to improve the early diagnosis of lung cancer and early surgery is essential to improve long-term survival.

Postoperative chemotherapy surgery can reduce tumor recurrence and metastasis, but there are certain side effects, the biggest drawback is to weaken the body's immune system [14] [15]. TCM take righting training methods can improve patient immunity ability; reduce chemotherapy-induced adverse reaction of the body [16]. Thus, lung cancer after treatment should be satisfied not only by chemotherapy, but early treatment with traditional Chinese medicine can significantly increase the survival rate of lung cancer after surgery.

\section{References}

[1] Xiao, D., Wang, C., Chen, H. and Hajek, P. (2013) Making Hospitals in China Smoke-Free: A Prospective Study of Implementing the New Standard. Nicotine \& Tobacco Research, 15, 2076-2080.

http://openurl.ebscohost.com/linksvc/linking.aspx?genre=article\&sid=PubMed\&issn=1462-2203\&title=Nicotine $\% 20 \mathrm{~T}$ ob\%20Res\&volume $=15 \&$ issue $=12 \&$ spage $=2076 \&$ atitle $=$ Making $\% 20$ hospitals $\% 20$ in $\% 20$ China $\% 20$ smoke-free: $\% 20 \mathrm{a}$ $\% 20$ prospective $\% 20$ study $\% 20$ of $\% 20$ implementing $\% 20$ the $\% 20$ new $\% 20$ standard.\&aulast $=$ Xiao \&date $=2013$ http://dx.doi.org/10.1093/ntr/ntt098

[2] Eriksen, M., Mackay, J. and Ross, H. (2013) The Tobcco Atlas. 4th Edition.

[3] Dusek, L., Muzík, J., Gelnarová, E., Fínek, J., Vyzula, R. and Abrahámová, J. (2010) Cancer Incidence and Mortality in the Czech Republic. Klinická Onkologie, 23, 311-324. http://www.scholaruniverse.com/profiles/people/070C030EAC1BA51A5258F6DC8D25D60F?h=cancer\%20incidence \%20mortality\%20czech\%20republic

[4] Lin, M.H., Huang, S.J., Shih, W.M., Wang, P.Y., Lin, L.H. and Hsu, H.C. (2013) Effects of an Anti-Smoking Program to Prevent Lung Cancer among Urban Aboriginals in Taiwan. Asian Pacific Journal of Cancer PRevention, 14, 64516457. http://dx.doi.org/10.7314/APJCP.2013.14.11.6451

[5] Shaykhiev, R. and Crystal, R.G. (2013) Basal Cell Origins of Smoking-Induced Airway Epithelial Disorders. Cell Cycle, 13, 311-324.

[6] Munshi, V. and McMahon, P. (2013) Importance of Smoking Cessation in a Lung Cancer Screening Program. Current Surgery Reports, 1, 4. http://dx.doi.org/10.1007/s40137-013-0030-1

[7] Gordon, J.S., Lichtenstein, E., Severson, H.H. and Andrews, J.A. (2006) Tobacco Cessation in Dental Settings: Research Findings and Future Directions. Drug and Alcohol Review, 25, 27-37. http://dx.doi.org/10.1080/09595230500459495

[8] Bullen, C. (2008) Impact of Tobacco Smoking and Smoking Cessation on Cardiovascular Risk and Disease. Expert Review of Cardiovascular Therapy, 6, 883-895. http://dx.doi.org/10.1586/14779072.6.6.883

[9] Savant, S.C., Hegde-Shetiya, S., Agarwal, D., Shirhatti, R. and Shetty, D. (2006) Effectiveness of Individual and Group Counseling for Cessation of Tobacco Habit amongst Industrial Workers in Pimpri, Pune-An Interventional Study. Asian Pacific journal of Cancer Prevention, 14, 1133-1139. http://dx.doi.org/10.7314/APJCP.2013.14.2.1133

[10] Singh, N. and Behera, D. (2013) Lung Cancer Epidemiology and Clinical Profile in North India: Similarities and Dif- 
ferences with Other Geographical Regions of India. Indian Journal of Cancer, 50, 291. http://dx.doi.org/10.4103/0019-509X.123581

[11] Chan, C.W., Richardson, A. and Richardson, J. (2013) An Investigation of a Symptom Cluster in Chinese Patients with Lung Cancer Receiving Radiotherapy. Contemporary Nurse, 45, 164-173. http://dx.doi.org/10.5172/conu.2013.45.2.164

[12] Rezaei, M.K., Nolan, N.J. and Schwartz, A.M. (2013) Surgical Pathology of Lung Cancer. Seminars in Respiratory and Critical Care Medicine, 34,770-786. http://dx.doi.org/10.1055/s-0033-1358558

[13] Garg, B., Sood, N., Sidhu, U.P. and Malhotra, V. (2013) Role of Fiberoptic Bronchoscopy and Utility of Bronchial Washings and Brushings in the Diagnosis of Lung Diseasesr. Indian Journal of Chest Disease and Allied Science, $\mathbf{5 5}$, 145-148.

[14] Søgaard, M., Thomsen, R.W., Bossen, K.S., Sørensen, H.T. and Nørgaard, M. (2013) The Impact of Comorbidity on Cancer Survival: A Review. Journal of Clinical Epidemiology, 5, 3-29. http://dx.doi.org/10.2147/CLEP.S47150

[15] Horita, N., Miyazawa, N., Morita, S., Kojima, R., Kimura, N., Kaneko, T. and Ishigatsubo, Y. (2013) Preoperative Chemotherapy Is Effective for Stage III Resectable Non-Small-Cell Lung Cancer: Metaanalysis of 16 Trials. Clinical Lung Cancer, 14, 488-494. http://dx.doi.org/10.1016/j.cllc.2013.03.006

[16] Lin, G., Li, Y., Chen, S. and Jiang, H. (2013) Integrated Chinese-Western Therapy versus Western Therapy Alone on Survival Rate in Patients with Non-Small-Cell Lung Cancer at Middle-Late Stage. Journal of Traditional Chinese Medicine, 33, 433-438. http://dx.doi.org/10.1016/S0254-6272(13)60144-2 